\title{
International Educational Market for Chinese Students: Marketing from Perspective of USA High Schools
}

\author{
Michael Nathanael LUETKE and Wen-ti XU \\ BeiHang University, Beijing, China
}

Keywords: Education, Marketing, Study abroad.

\begin{abstract}
Studying in the United States has become very popular among the Chinese. As a result colleges and high schools in the USA have been enrolling record numbers of Chinese. According to the United States studies report more than $30 \%$ of the international student population in the US are from China. Through survey and data collection this paper determines why so many Chinese are studying in the USA as early as their high school years. This study can help schools in the USA better prepare themselves for their international student body as well as highlight what the Chinese are seeking in an American education. Schools in the United States that are opening their doors to the Chinese market will need to be well informed about their targeted consumer. Marketing theory and marketing knowledge is becoming more and more vital to schools to attract the international student. Although education has not traditionally been regarded in the marketing sector it is clear that in our ever changing global environment schools will need to compete for the top students from around the world. Schools need to market themselves well to attract the Chinese student. Beyond the basic principles of marketing an in-depth study of the Chinese community is necessary to better attract the growing student body. Good business is always founded on good information. This study explores the top reasons why Chinese are studying in the USA as well as identifying what factors attract them to a particular school. The variety of the Chinese market adds an extra layer of complexity to this study. Differing groups hold strongly to differing values and purposes for choosing their future school. By breaking down the results of those surveyed into differing groups schools can better target those they are most interested in attracting to their school. Chinese international students are coming to the USA to study in record numbers and schools in the USA need to respond with better knowledge and understanding. Marketing techniques will better equip schools to attract, retain, and serve this growing consumer base.
\end{abstract}

\section{Introduction}

Education is one of the most valued commodities in China, and around the world. With a good education students can find good paying jobs and provide for their future life and family. Without an adequate education the job market and general life opportunities can be greatly limited. Chinese will go to any length to attain a good education and in their effort to attain this valued commodity will spend great effort, time, and resources.

Families in China can give up just about anything to educate their children. Parents will work in distant cities leaving their children in the care of their grandparents in order to make the money needed to provide a quality education. Entire families will relocate to different parts of cities or rent apartments closer to quality schools so that their children have the chance to study at top schools and minimize the commute time needed. Life for a young family in China has the appearance of revolving around the educational needs of their child.

\section{Background Literature}

The impact of globalization extends well beyond the realm of business and enterprise; it affects the cultural fabric of societies and educational institutions. Schools are becoming more international to respond to the impact of globalization. These two dynamically connected concepts work off of each other, where the former serves as "the catalyst" and the latter is " a response in a proactive way" [1]. 
Globalization leads to internationalization. Schools throughout the world are becoming a facilitator of internationalization. Recently there has been increasing call to internationalize the US curriculum, this reflects the public understanding that students require international skills and competencies in the new global environment.

The impact of the changing educational environment has also influanced many students' intercultural sensitivity. Paige reports that "education and training are known to play an important role in the development of an individual's intercultural sensitivity" [2]. As our world becomes increasingly integrated, cultural sensitivity must also rise to the challenge of living, studying and working with those of different backgrounds. As Bhawuk and Brislin suggested, "To be effective in another culture, people must be interested in other cultures, be sensitive enough to notice cultural differences, and then also be willing to modify their behavior as an indication of respect for the people of other cultures" [3]. Obviously adjustments in cultural perceptions need to happen in individuals for diverse individuals to live in harmony. The American Council for Education also has reflected this sentiment by making the following policy in 2002: "every postsecondary under-graduate experiences a curriculum designed to impart cross-cultural understanding and skills, an international dimension in the major field of study, and a broad understating of global issues" [4].

\section{Methodology}

In order to have a full understanding of the wide spectrum of variables, 120 surveys were administered to Chinese parents and students who plan to, or have, studied abroad. Non-responses were avoided and authenticity was assured by collecting data from those intimate to the researcher. As R.M. Groves states, "No matter what the framework of a survey is, its success relies on the active participation of the sampled households and businesses [5]. Of those surveyed 98 were students and 22 were parents of students; 57 were male leaving 63 female students; 46 considered themselves introverts while 74 considered them self an extrovert; 43 were Christian while 77 were non-Christian; and 53 preferred studied in the liberal arts field leaving 67 who preferred science and technology.

A three page survey (with room on the forth page for comments) was given to those planning to study or who have studied in the USA, asking them why they have chosen the USA for studies and then asking them how important were different factors in choosing the exact school they would/are attending. The twelve options for going to American for high school were given as: education in the USA is better, education in China is Poor, social skills and cultural experience, students can explore personal identity, stronger sports program, help improve English, help enter American university, good natural environment, safer environment, expected to send student to the USA, grow in faith and learn about religion, and better future and good job. Those surveyed were asked to rank their top three choices of those listed above.

Furthermore those surveyed were given twenty three reasons for choosing a particular high school and were asked to comment on how important each one of those reasons was in making their decision based on a Likert scale of 1 to 7 ( 1 meaning not important and 7 meaning most important). The reasons for choosing a particular high school were given as: school rank, reputation of the school, famous graduates, distance from nearest international airport, prefer schools in big cities, prefer schools in less populated country countryside, climate (average temperature, few storms or disasters), student body demographics (predominately White/ Black/ Hispanic/ Asian area), application to enter university after graduation, number of clubs and kinds of activities offered, what classes offered, number of AP (advanced placement) classes offered, food, size and scope of the school, ratio of American students to foreign students (especially Chinese students), sports offered, whether or not this is a religious school, is the school suitable for my education and help in development, prefer schools with dormitory living, prefer schools with home stay living, designated teacher specializing in helping international students integrate into American culture, and recommendation from others. Data from these questions were recorded into an Excel data base and results were analyses using basic statistical analysis. 


\section{Analysis of Data and Results}

Students choose to study in the USA for a wide variety of reasons. The majority of Chinese students have similar reasons for choosing the USA for their high school education. The top reasons selected for going to the USA are: "a better education in the United States" (20\%), "help in entering the university upon graduation" (15\%), "social skills together with cultural experience” (11\%), "the good natural environment” (12\%) and "growing in faith and learning more about religion” (11\%). These five reasons accounted for 70 percent of the top reasons listed by those surveyed for their top reason for going to the USA. Reasons that were not frequently selected include: "stronger sports program" (1\%), "safer environment” (3\%), "expected to study in the USA" (2\%), "poor education in China” (4\%), and "improving English" (6\%). Only 16 percent of the students choose one of these 5 as their top reason to study the USA. See Figure 1 below:

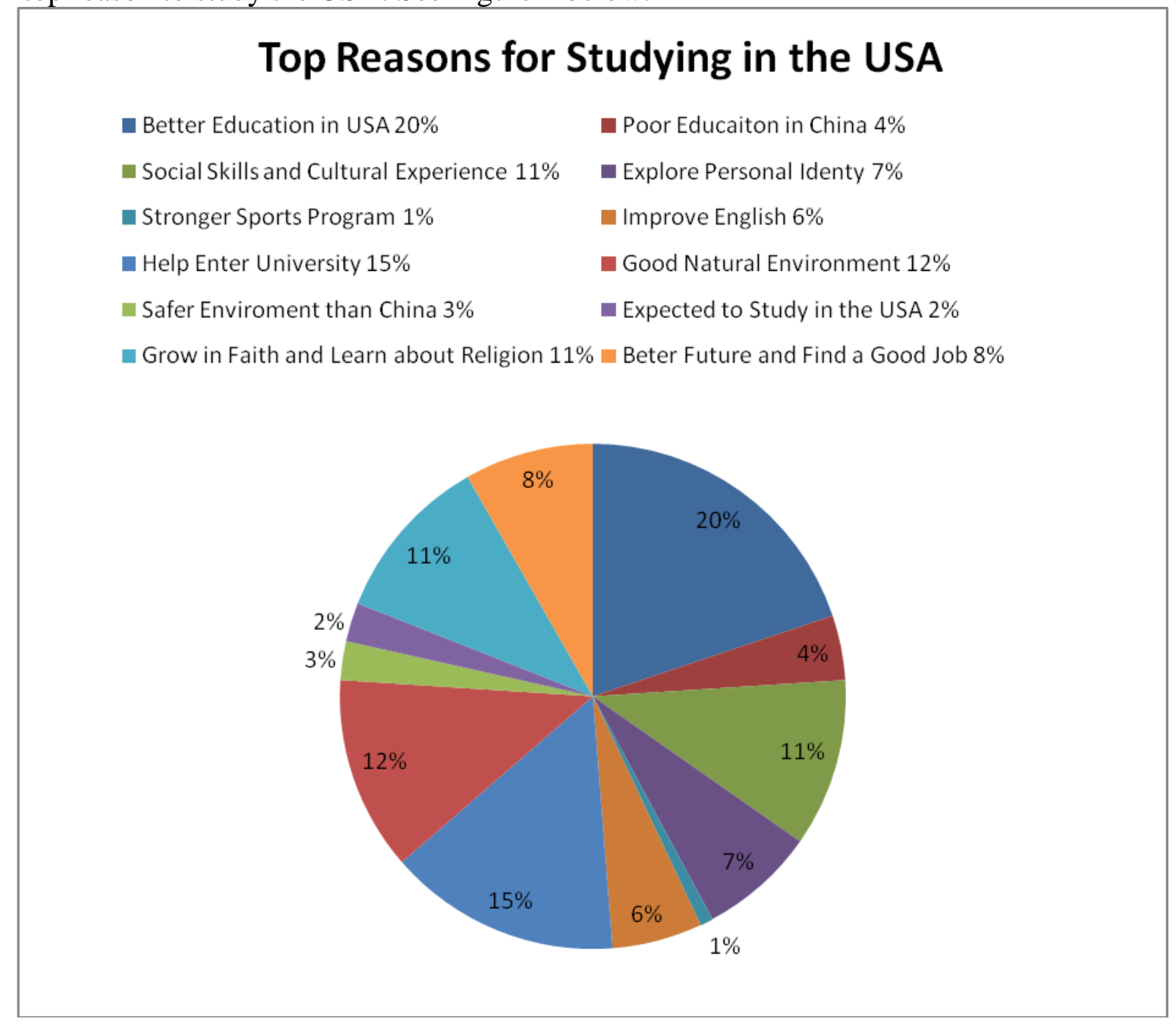

Figure 1. Top reasons for studying in the USA

Of the 23 further "reasons for choosing a particular high school" that were also proposed to the students and parents to be gauged on importance using the Likert Scale, four stand out as consistently relevant for their strong importance. The strongest reason of importance chosen on this survey was "suitable education and help in development." This reason was selected as important by $87 \%$ of those surveyed. This reason was strong among every demographic though it was chosen most often and to the highest degree by parents. "What classes are offered" and "number of AP classes offered" were also seen as important by a strong majority of those surveyed, $72 \%$ and $63 \%$ respectively. Approximately 64\% of all those surveyed considered a school that had a "teacher specializing in helping international students" of importance. This factor was especially strong among the parent demographic (78\%). Some reasons that were seen as unimportant were "prefer schools in less populated countryside" which only recorded $18 \%$ of those surveyed considering this as an important 
factor in choosing a school. The "distance from nearest international airport" also was shown to be of little importance with only $17 \%$ stating this is of importance. Female students did think that this airport factor was more important than male students as they did choose it of importance $20 \%$ of the time while males only chose it of importance $15 \%$ of the time. The most divided reason among any demographic was "whether or not this is a religious school." Among those in the Christian demographic $77 \%$ stated this was of importance while only $26 \%$ of those among non-Christians said this was of importance, though an additional 23\% stated they were indifferent.

\section{Summary}

Schools that are seeking to attract the Chinese international student should pay close attention to the factors that are of most importance to a Chinese family, notably maintaining a better perceived quality of education, helping graduates enter university, and building international students social skills and giving them a broad cultural experience. Schools that are targeting Christian families in China should also recognize that growing in faith and learning about religion is ranked very highly among Christian families in China while those students from a non-Christian family are mostly indifferent on this issue. Schools in America should also recognize the factors that are of most importance to Chinese families in choosing their particular school, these highest factors include: suitable education that is helpful in the development of the student, having a designated teacher to help international students, what classes and clubs are offered, as well as how many AP classes are avaliable. Schools that want to attract more students should pay more attention on these issues of high importance.

Schools in the USA should also understand what factors are not very important to their Chinese market, such as: strong sports program, proximity to the nearest international airport, and help in improving the student's English. There is thus no need to advertise or build such programs in order to attract the Chinese international student. Especially in the area of sports this point needs to be understood well. In American culture sports and recreation is elevated often above academics and students are recruited to schools based on the athletic program provided. Chinese culture places much less importance on the athletic program and more emphasis on the academics. Schools that advertise a strong sports program in their brochures and advertisements may be missing their target audience. High schools in the USA should focus on their quality of academics rather than their strong sports programs when recruiting Chinese students.

\section{References}

[1] Knight, J. (1999). Internationalization of higher education. In J. Knight (Ed.), Quality of internationalization in higher education (pp. 13-28). Paris: OECD.

[2] Paige, R. M. (1993). On the nature of intercultural experiences. In R. M. Paige (Ed.), Education for the intercultural experience (pp. 1-19). Yarmouth, ME: Intercultural Press.

[3] Bhawuk, D. P. S., \& Brislin, R. (1992). The measurement of intercultural sensitivity using the concepts of individualism and collectivism. International Journal of Intercultural Relations, 16(4), 413-436.

[4] ACE, (2002). American council on education, beyond September 11: a comprehensive national policy on international education. Council for institutional and international initiatives. Washington.

[5] Groves, R.M., D.A. Dillman, J.L. Eltinge, R.J.A. Little (2002). Survey Nonresponse, Wiley Series in Probability and Statistics. 